\title{
Cranial Nerve Involvement in Neuralgic Amyotrophy
}

Pietro E Doneddu*, Elia Sechi, Alberto Addis, Giulia Fadda, Chiara Fois and GianPietro Sechi

Department of Clinical and Experimental Medicine, University of Sassari, viale san Pietro, Sassari, Italy

*Corresponding author: Pietro Emiliano Doneddu, Dipartimento di Medicina Clinica e Sperimentale, UOC di Neurologia, Viale San Pietro 10, Sassari, 07100, Italy, Tel: +393934312740; +39079228233; Fax: +39079229150; E-mail: donpietros@hotmail.com

Received date: September 01, 2016; Accepted date: October 26, 2016; Published date: October 31, 2016

Copyright: (C) 2016 Doneddu PE, et al. This is an open-access article distributed under the terms of the Creative Commons Attribution License, which permits unrestricted use, distribution, and reproduction in any medium, provided the original author and source are credited.

\begin{abstract}
Neuralgic Amyotrophy (NA) is generally conceived as a multifocal neuropathy of the brachial plexus. However, different atypical forms with the involvement of other peripheral nerves, such as the lumbosacral plexus, the intercostal and the phrenic nerve and the cranial nerves (CNs), have been reported in the literature. In an attempt to shed more light on the atypical presentation of NA with $\mathrm{CN}$ involvement, we summarized the most relevant features of all cases of idiopathic NA with CN palsy, published up to January 2016. CN involvement in NA usually occurs with concomitant classic brachial plexopathy. Less frequently, $\mathrm{CN}$ palsy is the unique manifestation of the syndrome. In these cases, clinical suspicion and imaging studies are essential for a correct diagnosis, which may have therapeutic and prognostic relevance.
\end{abstract}

Keywords: Neuralgic amyotrophy; Brachial neuritis; Idiopathic brachial plexopathy; Cranial nerve; Cranial nerve palsy; Cranial neuropathy

\section{Introduction}

Neuralgic Amyotrophy (NA) is a multifocal neuropathy that comprises an idiopathic (INA) and a hereditary form (HNA). It generally presents with a classic phenotype ("typical form") characterized by acute-onset of severe shoulder pain followed, hoursdays later, by weakness and wasting of the shoulder girdle and arm muscles with multifocal distribution.

Focal sensory loss also occurs but motor manifestations are typically much more pronounced on examination. Apart from this typical form, NA can also manifest with involvement of other peripheral nerves, such as the cranial nerves (CNs), the lumbosacral plexus, the intercostal nerves and the phrenic nerve ("atypical forms").

Although it has always been considered to be rare, a recent study found that typical form of NA is $30-50$ times more common than previously thought. The authors concluded that unawareness of the clinical presentation of NA is the most likely explanation for this difference [1]. Considering that the atypical forms of NA, which account for over $30 \%$ of all cases [1], are even less familiar to general practitioners than the classic one, it is reasonable to assume that they too are far underrecognized.

Cranial nerve involvement is one of the uncommon presentations of NA, and seems to occur more frequently in HNA. In the largest series, the recurrent laryngeal nerve was the only $\mathrm{CN}$ reported to be affected, accounting for $2.6 \%$ of 199 patients with INA and $18.6 \%$ of 47 patients with HNA [2]. However, several case reports and small case series have shown that $\mathrm{CN}$ involvement in NA can be highly heterogeneous, further complicating the diagnosis.
In an attempt to shed more light on this atypical presentation of NA, we have tried to summarize in this paper the most relevant features of all published cases of NA with CN palsy.

\section{Methods}

A review of the English literature from PubMed was performed up to January 2016 with the following search terms: neuralgic amyotrophy, Parsonage-Turner syndrome, idiopathic brachial plexopathy, brachial neuritis. Among them, cases of INA with CN involvement were sorted out.

\section{Results}

A total of 22 cases were identified (15 male; 3 female; 4 notspecified) (Table 1) [3-19]. Median age at onset was 47 years (range 5-82). Vagus nerve (CN X) was the most frequently affected, followed by XI, IX and XII and VII CNs. The CNs were involved either alone (9 cases) or in combination (13 cases). The most frequent associations were the bilateral involvement of the X nerve ( 3 cases) and of IX-X-XIXII nerves in combination ( 3 cases).

The most frequent mononeuropathies were recurrent laryngeal nerve palsy (3 cases) and XI nerve palsy (3 cases). Comprehensively, CNs were affected unilaterally in 15 cases $(68 \%)$ and bilaterally in 7 cases (32\%). In two cases, CN palsy occurred without a simultaneous clinically overt brachial plexopathy (in one case paralysis of the right supraspinatus appeared only after 2-month follow-up, in the other case the impairment of the brachial plexus was documented only with electromyography).

The phrenic nerve was affected in 6 cases (not shown in Table). Interestingly, 3 of these where asymptomatic and phrenic nerve involvement was detected by standard chest X-ray. Three cases had recurrences. 


\begin{tabular}{|c|c|c|c|c|c|c|c|c|c|}
\hline Cases & Age & Sex & VII & IX & $\mathbf{x}$ & $\mathbf{X I}$ & XII & $\begin{array}{l}\text { Neurological examination of the } \\
\text { upper-limb }\end{array}$ & EMG \\
\hline Bradley et al. [3] & 32 & M & & $\mathrm{R}$ & LR & & & $\begin{array}{l}\text { R. delt., R. supraspin., R. infraspin., R. } \\
\text { bic., R. hemidiaph., other muscles of the } \\
\text { R. arm (not specified) }\end{array}$ & $\begin{array}{l}\text { R. delt., R. supraspin., R. infraspin., R. } \\
\text { bic., R. hemidiaph., other muscles of the } \\
\text { R. arm (not specified) }\end{array}$ \\
\hline Dinsmore et al. [4] & 19 & M & & & LR & & & $\begin{array}{l}\text { delt. (bilat), supraspin.(bilat), infraspi. } \\
\text { (bilat), bic. (bilat), tric. (bilat), forearm } \\
\text { muscles (bilat), R. hemidiaph. }\end{array}$ & Not specified \\
\hline Byrne et al. [5] & 30 & M & $\mathrm{R}$ & & & & & R. bic., R. tric., R. wrist ext., R. ext. digit. & R. first dors.inteross., R. tric., R. frontalis \\
\hline Byrne et al. [5] & 48 & M & $\mathrm{L}$ & & & & & $\begin{array}{l}\text { R. supraspin., R. infraspin., R. bic., R. } \\
\text { serr. ant. }\end{array}$ & $\begin{array}{l}\text { R. delt., R supraspin., } R \text { infraspin., } R \text {. } \\
\text { tric. }\end{array}$ \\
\hline Byrne et al. [5] & 31 & M & & & & $\mathrm{L}$ & & $\begin{array}{l}\text { L. delt., L. supraspin., L. infraspin., L. } \\
\text { bic. }\end{array}$ & Not reported \\
\hline Sanders et al. [6] & 48 & M & & & $\mathrm{L}$ & & & L. delt., L. supraspin., L. infraspin. & L. delt., L. supraspin., L. infraspin., L. bic. \\
\hline Pierre et al. [7] & 55 & M & & $\mathrm{R}$ & $\mathrm{R}$ & $\mathrm{R}$ & $\mathrm{R}$ & R. romb., R. supraspin., R. infraspin. & $\begin{array}{l}\text { R. romb., R. supraspin., R. infraspin., L. } \\
\text { suprascap., delt (bilat) }\end{array}$ \\
\hline To et al. [8] & 5 & M & & & LR & L & & "Left shoulder weakness", R. hemidiaph. & L. supraspin., L. infraspin., delt. (bilat) \\
\hline Hyde et al. [9] & 24 & $\mathrm{~F}$ & & & LR & & & $\begin{array}{l}\text { delt. (bilat), infraspin. (bilat), bic. (bilat), } \\
\text { tric. (bilat), R. serr. ant., L. infraspin., }\end{array}$ & $\begin{array}{l}\text { L. upper trunk muscles in a patchy } \\
\text { pattern, thyroarytenoid muscles }\end{array}$ \\
\hline Cruz-Martinez et al. [10] & - & - & & & & $\mathrm{x}$ & & Not reported & Not reported \\
\hline Cruz-Martinez et al. [10] & - & - & & & & $\mathrm{x}$ & & Not reported & Not reported \\
\hline Cruz-Martinez et al. [10] & - & - & LR & & & $\mathrm{x}$ & & Not reported & Not reported \\
\hline Cruz-Martinez et al. [10] & - & - & LR & & & & & Not reported & Not reported \\
\hline Chen et al. [11] & 62 & M & & & $\mathrm{L}$ & & & $\begin{array}{l}\text { delt. (bilat), supraspin. (bilat), infraspin. } \\
\text { (bilat), bic.(bilat), brachior. (bilat), L. } \\
\text { hemidiaph. }\end{array}$ & $\begin{array}{l}\text { delt.(bilat), supraspin. (bilat), infraspin. } \\
\text { (bilat), bic. (bilat) }\end{array}$ \\
\hline Holtbernd et al. [12] & 55 & M & & & LR & & & $\begin{array}{l}\text { hemidiaph. (bilat) R. supraspin (noted at } \\
\text { 2-month follow-up. Initially normal) }\end{array}$ & Normal \\
\hline Skeikh et al. [13] & 82 & M & & $\mathrm{L}$ & $\mathrm{L}$ & L & L & L. serr. ant., L. delt., L. hemidiaph. & Not reported \\
\hline Samarà et al. [14] & 65 & $\mathrm{~F}$ & & & $\mathrm{R}$ & & & $\begin{array}{l}\text { R. arm abduction muscles (not } \\
\text { specified) }\end{array}$ & Not reported \\
\hline Zuberbuhler et al. [15] & 56 & $\mathrm{~F}$ & & $\mathrm{~L}$ & $\mathrm{~L}$ & $\mathrm{~L}$ & L & $\begin{array}{l}\text { L. delt., L. supraspin., L. infraspin., L. } \\
\text { bic., L. tric., L. pron. teres, L. supin., L. } \\
\text { flex. digit., L. ext. digit. }\end{array}$ & $\begin{array}{l}\text { L. delt. R. delt.(EMG performed during } \\
\text { the recovery period) }\end{array}$ \\
\hline Pinto et al. [16] & 15 & M & & & $\mathrm{R}$ & $\mathrm{R}$ & & R. serr. ant., R. delt. & R. trap., delt. (bilat) \\
\hline de Oliveira et al. [17] & 15 & M & & & $\mathrm{R}$ & $\mathrm{R}$ & & Not reported & Normal \\
\hline Genevray et al. [18] & 46 & M & & & & & $\mathrm{R}$ & R flex. poll. long., R. serr. ant. & $\begin{array}{l}\text { R. serr. ant., R. supraspin., R. bic., R. } \\
\text { flex. poll. long. }\end{array}$ \\
\hline Doneddu et al. [19] & 72 & M & & $\mathrm{R}$ & $\mathrm{R}$ & $\mathrm{R}$ & & Normal & delt. (bilat), L. infraspin. \\
\hline
\end{tabular}

Table 1: Neuralgic amyotrophy cases presenting with cranial nerve involvement. [BP: Brachial Plexus; X: side not specified; R.: Right; L.: Left; bilat.: bilateral; delt.: deltoid; trap.: trapezius; bic: biceps; tric: triceps; serr. ant: serratus anterior; flex. poll. long: flexor pollicis longus; supraspin.: supraspinatus; infraspin: infraspinatus; hemidiaph: hemidiaphragm; romb: romboid; flex. digit: flexor digitorum; ext. digit: extensor digitorum; brachior: brachioradialis; pron. teres: pronator teres; first dors. inteross.: first dorsal interosseus; wrist ext: wrist extensors].

\section{Discussion and Conclusion}

The diagnosis of NA with concomitant $\mathrm{CN}$ impairment requires clinical suspicion, especially in cases without a clinically overt brachial plexopathy. Patients may complain inspiratory stridor, dysphonia or dysphagia, facial weakness, and shoulder ptosis, solely or in varying combinations. In this clinical setting, the finding of a simultaneous clinical involvement of the brachial plexus should lead the physician to suspect NA. However, it is important to keep in mind that since the 
trapezius muscle helps stabilize the shoulder; its weakness may lead adjacent muscles to appear clinically weak. In addition, since movements of the shoulder in this context are usually painful, disuse atrophy in adjacent muscles of the brachial plexus can also occur [20].

When $\mathrm{CN}$ abnormalities are present, the first clinical step should be to rule out masses or infiltrative processes along the course of the affected nerve(s) through CT or magnetic resonance imaging studies. Indeed, focal lesions along the course of $\mathrm{CNs}$ can sometimes mimic NA [20]. For this purpose, also electromyography (EMG) may be useful in revealing an impairment of other peripheral nerves not anatomically contiguous or even controlateral to the $\mathrm{CNs}$ affected, as shown in one case [19].

Indeed, this latter finding is more likely due to a multineuropathy rather than a structural process such as nerve compression or local infiltration. However, EMG cannot replace imaging studies in this role, and its results must be interpreted with caution because localizing pitfalls due to the close proximity of the trapezius muscle with other shoulder muscles are possible.

In addition to structural lesions, other causes of brachial plexopathy in association with $\mathrm{CN}$ palsy must be excluded before considering the diagnosis of NA, such as VZV, HIV, Lyme disease, radiation-induced neuropathy, vasculitis, lymphoma, and sarcoidosis. Diagnostic clues that could be helpful in distinguishing NA from these conditions include predominance of motor symptoms, multifocal distribution of weakness, severe analgesic-resistant pain preceding the onset of $\mathrm{CN}$ palsy by days or few weeks, and a positive history of an antecedent event (infection, surgery, physical strain, childbirth).

Once other causes have been excluded, EMG should be performed in order to confirm a multifocal pattern of involvement of the brachial plexus or even detect it in cases where $\mathrm{CN}$ palsy is the unique manifestation of the syndrome. In addition, EMG is helpful in determining the grade of denervation and in estimating the degree of recovery. Finally, chest X-ray may reveal phrenic nerve palsy even in patients not complaining dyspnea $[3,4,13]$.

In conclusion, NA with CN palsy usually occurs with a concomitant clinically overt brachial plexopathy. In these cases, the diagnosis relies mostly on clinical examination and EMG, both demonstrating a multifocal, predominantly motor impairment of the brachial plexus, and on the exclusion of other possible causes. Less frequently, CN impairment can occur without a clinically overt involvement of the brachial plexus. Patients present with symptoms that are unusual for $\mathrm{NA}$ and that can mislead the physician. In this setting, clinical suspicion and imaging studies are essential for a correct diagnosis, which may have therapeutic and prognostic relevance.

\section{References}

1. van Alfen N, van Eijk JJ, Ennik T, Flynn SO, Nobacht IE, et al. (2015) Incidence of neuralgic amyotrophy (Parsonage Turner syndrome) in a primary care setting--a prospective cohort study. PLoS One 10: e0128361.
2. van Alfen N, van Engelen BG (2006) The clinical spectrum of neuralgic amyotrophy in 246 cases. Brain 129: 438-450.

3. Bradley WG, Madrid R, Thrush DC, Campbell MJ (1975) Recurrent brachial plexus neuropathy. Brain 98: 381-398.

4. Dinsmore WW, Irvine AK, Callender ME (1985) Recurrent neuralgic amyotrophy with vagus and phrenic nerve involvement. Clin Neurol Neurosurg 87: 39-40.

5. Byrne E (1987) Extended neuralgic amyotrophy syndrome. Aust N Z J Med 17: 34-38.

6. Sanders EA, Van den Neste VM, Hoogenraad TU (1988) Brachial plexus neuritis and recurrent laryngeal nerve palsy. J Neurol 235: 323.

7. Pierre PA, Laterre CE, Van den Bergh PY (1990) Neuralgic amyotrophy with involvement of cranial nerves IX, X, XI and XII. Muscle Nerve 13: 704-707.

8. To WC, Traquina DN (1999) Neuralgic amyotrophy presenting with bilateral vocal cord paralysis in a child: A case report. Int J Pediatr Otorhinolaryngol 48: 251-254.

9. Hyde GP, Postma GN, Caress JB (2001) Laryngeal paresis as a presenting feature of idiopathic brachial plexopathy. Otolaryngol Head Neck Surg 124: 575-576.

10. Cruz-Martínez A, Barrio M, Arpa J (2002) Neuralgic amyotrophy: variable expression in 40 patients. J Peripher Nerv Syst 7: 198-204.

11. Chen YM, Hu GC, Cheng SJ (2007) Bilateral neuralgic amyotrophy presenting with left vocal cord and phrenic nerve paralysis. J Formos Med Assoc 106: 680-684.

12. Holtbernd F, Zehnhoff-Dinnesen AA, Duning T, Kemmling A, Ringelstein EB (2011) An unusual case of neuralgic amyotrophy presenting with bilateral phrenic nerve and vocal cord paresis. Case Rep Neurol 3: 69-74.

13. Sheikh NR, Henderson RD (2011) Subacute unilateral cranial and cervical polyneuropathies. J Clin Neurosci 18: 734.

14. Samarà L, Valls-Sole J, Caballero M (2013) Dysphonia as an unusual debut of Parsonage-Turner syndrome. Head Neck 35: E229-230.

15. Zuberbuhler P, León Cejas LV, Binaghi D, Reisin RC (2013) Acute brachial plexus neuropathy with involvement of cranial nerves IX, X, XI and XII. J Neurol Sci 334: 169-171.

16. Pinto MV, Joffily L, Vincent MB (2013) Recurrent vocal fold paralysis and parsonage-turner syndrome. Case Rep Otolaryngol 2013: 763201.

17. Oliveira AG, Pinho MM (2014) Extended neuralgic amyotrophy syndrome: Voice therapy in one case of vocal fold paralysis. Codas 26 : 175-180.

18. Genevray M, Kuchenbuch M, Kerbrat A, Sauleau P (2016) Unusual presentation of neuralgic amyotrophy with impairment of cranial nerve XII. Muscle Nerve 54: 335-336.

19. Doneddu PE, Sechi E, Addis A, Fadda G, Fois C, et al. (2016) Neuralgic amyotrophy mimicking Vernet syndrome. J Neurol Sci 362: 230-231.

20. Larson WL, Beydoun A, Albers JW, Wald JJ (1997) Collet-Sicard syndrome mimicking neuralgic amyotrophy. Muscle Nerve 20: 1173-1177. 